Article

\title{
Sustainable Mobility in the Mobile Risk Society-Designing Innovative Mobility Solutions in Copenhagen
}

\author{
Malene Freudendal-Pedersen ${ }^{1, *(\mathbb{D})}$, Katrine Hartmann-Petersen ${ }^{2}$, Freja Friis ${ }^{3}{ }^{\mathbb{D}}$, \\ Malene Rudolf Lindberg ${ }^{1}$ and Thomas Skou Grindsted ${ }^{2}$ \\ 1 Department of Planning, Aalborg University, 9000 Aalborg, Denmark; malene@plan.aau.dk \\ 2 Department of People and Technology, Roskilde University, 4000 Roskilde, Denmark; \\ katrineh@ruc.dk (K.H.-P.); tskoug@ruc.dk (T.S.G.) \\ 3 Department of the Built Environment, Aalborg University, 2400 Copenhagen SV, Denmark; frf@build.aau.dk \\ * Correspondence: mfp@plan.aau.dk
}

Received: 17 July 2020; Accepted: 31 August 2020; Published: 3 September 2020

check for updates

\begin{abstract}
The issue of creating more sustainable mobility systems has been revisited during the past 50 years. So far, we are still waiting for an innovative systemic change that is not simply an iteration of existing technologies. This standstill is to a large degree due to the hegemonic mobility paradigm, working under a "predict and provide"-driven approach, with little attention being paid to environmental and social externalities. This paper calls for a new understanding of mobility transition interlinked with the cultural values of modern societies, deeply rooted in the mobile risk society. To create sustainable mobility practices we need robust, socially coherent, and inclusive mobility systems that are more than just transportation systems and connections. The empirical starting point is a visionary workshop on designing "Sustainable Innovative Mobility Solutions" in three urban areas in Copenhagen. The workshop created a cross-disciplinary space for actors to meet across dominant silos and acknowledge the need for intervention framings to focus on innovation as a matter of interlinking sustainable mobilities practices within everyday living in a mobile risk society.
\end{abstract}

Keywords: mobility; mobile risk society; innovation; iteration; visionary workshop

\section{Introduction}

Ongoing discussions about sustainable mobility systems underline that climate change mitigation requires the decarbonization of the mobility sector [1]. The Agenda 21 blueprint from the UN Rio Summit in 1992 was the first to outline transportation as an important focus, and in 2004, this was further developed in the report "Mobility 2030: Meeting the Challenges to Sustainability" by the World Business Council for Sustainable Development. So far, these attempts have not resulted in the change needed. Instead, in the EU the overall growth in energy consumption due to transportation increased by $34 \%$ from 1990 to 2016, alongside lower passenger cars prices encouraging a growth in private vehicles [2]. According to Beck [3], the dynamics of post-industrial societies are increasingly challenged by "self-produced" risks such as climate change, carbon pollution, and congestion. Socio-cultural change, therefore, is not so much the consequence of intended policies and strategic decisions; rather, change is propelled by the need to limit the negative side effects or unintended consequences. This is what Beck [3] termed the "risk society".

Within mobilities research, this is further developed into the concept of the "mobile risk society" $[4,5]$, that sees these self-produced risks as unintended consequences of the ongoing mobilization of modern societies. In public debate, mobility is often seen as synonymous with 
transportation. Within the mobilities paradigm, focus is on understanding the multitude of physical and virtual movement in connection and with its social and cultural impact. The plural in "mobilities" underlines the interconnectedness. The mobilities turn within social sciences was initiated by John Urry in his book Sociology Beyond Societies: Mobilities for the Twenty-First Century from 2000, which strongly encouraged moving beyond the idea of society as a fixed container to instead understand it through its immense mobilities, very much in line with Beck's idea of cosmopolitanism $[6,7]$.

This creates an opposite to the dominating response to the decarbonization of the mobility sector that is based purely on the implementation of new technologies to make cities and their mobilities more sustainable. The transformation of the automotive industry, currently taking place all over the world, is an example of this by its emphasis on electrification, new battery technologies, automation, smart mobility, etc., which all stand for an iteration of the current system. It is a continuation of the "system of automobility" [8]. The innovation in sustainable mobility systems lies in changing mobility cultures towards less car-dependency and a smaller part of the automotive industries' transformation where sharing mobilities-Mobility-as-a-Service (MaaS)—can play a role here. This is also a focus in the Sustainable Development Goals, in which some recommendations have altered the focus and suggest using "a tailored 'Avoid-Shift-Improve' approach ... to promote a combination of multimodal, collective-shared mobility solutions and sustainable transport systems." [9]. In other words, the innovation lies in changing the automobility system and vulture which has dominated urban and rural landscapes for the last 100 years.

In this article we discuss sustainable innovation approaches and the mainstream approaches of iteration in the mobile risk society. The assumption is that the current standstill in achieving a sustainable mobility situation demands more than waiting for ground-breaking technological solutions. Instead, innovation in many ways is also about harvesting the "low-hanging fruits" of existing innovative mobility- and non-mobility-related solutions. The emergence and reinvention of sustainable mobility cultures often happens unplanned and uncontrolled at different levels and in different places and niches. Mobility culture is embedded in socio-technological environments and highly influenced by planning and the quality and structures of built environments. The making of sustainable cities and communities (SDG goal 11) is based on combining the technocratic planning ideal with all the things mobilities in cities also are, apart from speed, efficiency, and accessibility [10]. If we are to take the sustainable development goal seriously, efficiency alone will not do the job.

How to structure existing and future cities, and their mobilities, is also a question of how to "design" the social layout and human interactions, and this needs to have a greater influence on transportation and mobility planning [11,12]. When planning urban mobility, there is a tendency to focus on the societal and political acceptance and legitimacy of the measures required. This is most often done based on existing data, models, and calculations. By investigating urban projects, emphasis is instead placed on the modifications of social configurations within neighborhoods and everyday life through the implementation of urban projects. These kinds of "data" do not show up in data sets, models, or simulations. This lack of data when planning cities was already highlighted by Jan Gehl in 1966 (2011 in the English version) in his book Life Between Buildings [13], which addressed the importance of holistic (sustainable) planning for urban life.

What is most often either overlooked or taken for granted is the change in everyday practice that needs to follow when transforming current mobility practice or adjusting to new technologies. The everyday slow time and rhythms are rarely consciously reflected or dealt with and, as such, are difficult to handle at the planning stage [14-17]. The organization of urban space and access to it go hand in hand with changing the relationships between people and mobility artefacts. Instead of searching for the "one-best-way" solution, this might provide an opening to experiment with possible solutions at a time where mobilities have an even greater impact on modern economies, cultures, and cities $[18,19]$.

As an example, to discuss how innovation can take place, the article presents data from a visionary workshop on "developing innovative sustainable mobility solutions" in three urban areas in 
Copenhagen. This is part of the "Sustainable Innovative Mobility Solutions" (SIMS) project (funded by Innovation Fund Denmark, 2019-2023), which aims to understand the multiple social practices, perceptions, and patterns on which everyday life in the mobile risk society is organized. The workshop focused on developing non-car-dependent, sustainable urban mobility solutions, with specific focus on interlinked mobilities in urban everyday life. The workshop showed that alternative mobile futures need to think across silos and interlink the multitude of mobilities practices. The results do not represent a radical change in the distribution of transportation modes on the streets-however, then again, it does indicate a shift in not placing private cars at the top of the hierarchy and lays out new ground for interactions between mobility and the city by acknowledging the great potentials of urban everyday life and communities. For many outside observers, Denmark is perceived as a place that already have a high amount of sustainable mobilities and a unique mobility culture. We are not trying to argue this is not so. However, even with the high amount of cycling (61\% of the daily commute for Copenhageners) the car ownership is still increasing, and the commute on cycling decreases when moving away from the central Copenhagen. In this sense we argue that the car culture is still very prevalent in Denmark and stands as the biggest challenge when working towards sustainable mobilities. The SIMS research project and the workshop, used as an example in this paper, addresses this by thinking together with stakeholders on how to alter the perception of car ownership as a necessary element in everyday life.

The article starts by discussing the relation between innovation and iteration, in what constitutes the majority of suggestions for creating more sustainable mobility, that is to a large degree due to a hegemonic mobility paradigm, working under a "predict and provide"-driven approach, with little attention to environmental and social externalities. This is followed by a discussion of how mobility cannot be defined primarily as an issue of new technologies, but instead needs to be interlinked with the cultural values of modern societies, deeply rooted in living in a mobile risk society. Before moving on to the workshop, a discussion on participatory planning and storytelling places the workshop in the Copenhagen context. This forms the background for understanding what makes the workshop in the SIMS project an interesting example of alternative problem framings that could challenge the hegemonic dominant approaches. The article concludes with reflections on specific means for opportunities to create sustainable, socially coherent, and inclusive mobility systems that are more than just transportation systems and connections.

\section{Innovation and Iteration in Mobility Systems}

During the past 40 years, mobility systems have hardly been subjected to radical sustainable innovations [20]. Rather, mobility systems follow the trajectories of the great acceleration [21] in which transportation accounts for around one quarter of the total greenhouse gas emissions globally [22-24]. Given the huge $\mathrm{CO}_{2}$ emissions accompanied by a trebling of petroleum consumption [21,25], the talk about innovation in sustainable mobilities seems somehow mostly polemic. Rather, William Stanley Jevons' paradox [26] applies, where greater energy efficiency of the steam engine leads to an overall increased demand. "Now the same principles apply, with even greater force and distinctness, to the use of such a general agent as coal. It is the very economy of its use which leads to its extensive consumption. It has been so in the past, and it will be so in the future. Nor is it difficult to see how this paradox arises" [26] (p. 6). Of the total consumption of petroleum products in the EU, in 2016 the transport sector consumed $66 \%$, or 345 Mtoe (million tons of oil equivalent), and it continues to increase approximately $2 \%$ per year [27]. Since the invention of the car, scientists, car manufactures, and entrepreneurs have made iterations that have improved cars in relation to energy efficiency, reliability, safety, etc., over the course of the past four decades. For the entire mobility system, however, the pile of iterations has not exceeded the energy-related "demand for mobility" [16]. While each niche innovation becomes more energy efficient, the net demand has increased 48\% since 1985 in the EU alone [2]. These actors signify "environmental innovation", and yet extend anthropogenic climate risk by iterating path dependencies of carbon use. To achieve the climate goals from the 2020 Paris agreement [2,27], transportation emissions must be reduced by 66-94\% from 2005 levels 
and this is difficult to imagine as long as iterations in automobilities orchestrate mobility cultures of organized climate path dependencies. They reproduce the system of automobility [8] and in this way iterations can operate as salient and often unacknowledged barriers to low-carbon transitions when they deploy culturally appropriate solutions to the climate crises. Thus, contemporary mobility cultures interlock "silos of techno innovations", and the deeply culturally embedded belief in technological innovation and energy efficiency produces solutions that remain structurally organized into their silos (niches of iterations).

It can be argued that smart cities, digitalization, and artificial intelligence (AI) combined with autonomous vehicles (AVs) and multiple mobilities-physical, digital, virtual, communicative, imaginative, etc.-create mobilities systems significantly different from earlier days. In addition, the combination of $\mathrm{AI}$ and $\mathrm{AVs}$ are presented as radical sustainable mobility system innovations, as dominant discourses around smart cities merge with political governance of sustainable cities and green growth [28]. Worldwide, AVs in combination with smart cities promises great potential to fix the existing unsustainable mobility regime. Such technologies endeavor to manage, monitor and optimize areas of city operations. Transportation flows are progressively being translated into codes and data, forming a software-defined platooning paradigm for urban mobility. While smart cities and AVs prove radical innovations of their own, at system level they might be subject to mobility iterations only-iterations that substitute Jevons' paradox [3] by shutting in the automobility system further, as they encrypt, predict, and provide imperatives. Smart city technologies and AVs clearly optimize many aspects of urban mobility. Nevertheless, smart city developments have few mechanisms (if any) to ensure radical system innovations. The history of urban planning demonstrates how smart cities, digital cities, cyber cities, intelligent cities, and other techno-idealistic conceptualizations [29,30] have embarked on sustainable, resilient, and eco-friendly cities. Nevertheless, the past 40 years of techno-idealistic discourses for energy-efficient mobility, smart cities, etc. [28], follow the trajectories of the Jevons paradox. In consequence, we argue that smart cities-and associated mobility trajectories-risk continuing the automobility system (whether automated, electrified, or not) rather than cutting across silo thinking. Existing modeling approaches cannot extrapolate this due to the uncertain nature of AVs [31], but the cultural politics of predicting and providing model projections suggest that $\mathrm{AVs}$ increase transportation work and carbon emissions by up to $20 \%$ [32], shifting more people from walking, cycling, and public transportation towards an AV mobility service with negative health effects as a result [32-34].

Systematic risk in mobility systems seem contradictory in itself and it becomes increasingly clear that these linear modernization strategies of techno-optimism create social inequalities, negative side effects, and counterproductive impacts [35]. Instead, technology innovation or iterations need a shift toward radical social and cultural innovations. This calls for the automobility system to also engaging with mobility cultures and policies for a low-carbon transition.

\section{Cultures of Mobility in the Mobile Risk Society}

Theories of risk society $[3,36,37]$, the new mobilities paradigm $[7,38]$ and the mobile risk society $[4,6]$ argue that coping with climate change and systemic risk starts from understanding mobilization and globalization as general principles of modern life. The risk-inducing and carbon-reliant mobility system is an integrated part of contemporary everyday life and the mobility system's materials and cultures are essential for the commute to work, consumption of goods, meeting with friends, sharing ideas, picking up children, etc. Modern life is thus permeated by cultures of mobilities. By taking modern everyday life as the scale of observation, there emerges a perspective for understanding mobilities in a world at risk and for engaging with sustainable mobility innovations as more than just technology inventions. In everyday life, current cultures of mobilities appear as a mixture of technologies, social practices, and structural patterns deeply rooted in the mobile risk society [4,5]. The concept of mobile risk society was first developed by Kesselring [4] and synthesizes theories of reflexive modernization and the risk society [3,36] and the new mobilities paradigm framed by Sheller and Urry [38]. The formulation 
of risk society followed Beck's analysis of contemporary technological and ecological natural and self-produced risks just before the Chernobyl accident in 1986 [3]. The uncertainties, insecurities, and unintended consequences of political decisions and technological development have become a driving force in modern societies, because risks demand urgent political and social action to limit the negative side effects of economic, political, and social activities. Just recently, we experienced how risks induced radical social and economic changes with the breakout of COVID-19 and the world-wide societal lock-down that followed. However, even just before the Chernobyl accident, Beck argued that extensive risks were transforming society towards a new modernity [3]. Whereas the first modernity was characterized by stability, unambiguity, ideology, class distinctions, and other familiar demarcation lines providing life with direction, orientation, and predictability, the second modernity is characterized by risk, ambivalence, and insecurity $[3,4,39]$. Certainty is replaced by a condition of general insecurity, uncertainty, and ambivalence, forcing individuals to navigate a risky world without the social markers and clear guidance of previous times. Beck is not arguing that the conditions of first modernity are disappearing in the second modernity, rather they co-exist, overlap, and merge with the second modernity.

Members of the risk society are not necessarily confronted with more risks than their ancestors. However, in a world of dissolving institutions, responsibility for tackling socially produced risks is passed on to individuals, and it follows that risks are present in new ways in everyday life [40]. Risks of first modernity was embedded in the life path structured by tradition. In the second modernity old and new risks are constantly assessed by the reflexive individual: Is my gender and class the reason my wages are lower? Are local greenhouse vegetables less harmful to the environment than foreign ones? Is it safe enough to use public transportation during the Corona crisis? Can I trust this article on Facebook? Are diesel cars better than gasoline cars? The risk bombardment creates a high demand for expert knowledge, reflexivity, and rapid decision-making. Coping with risks becomes part of the everyday apparatus, a permanent condition of the reflexive, compressed everyday life in the risk society $[3,40]$.

The mobile risk society emerges from combining the uncertainty, insecurity, and ambivalence of the risk society with the new mobilities paradigm's idea of movement as the general principle of modernity and concern with flows and networks of people, objects, and ideas [7,38]. Synthesizing these traditions, Kesselring develops a tripartite scheme of modernity $[4,39]$, schematizing how mobility has transitioned through the different phases of modernity, from a first to a second and even a third phase. Kesselring's mobile risk society; thus, elaborates on Beck's ideas about a society transitioning towards new forms of modernity in combination with mobilities research's perception of mobility as a fundamental principle of modernity. In the first phase of modernity, the train is the ideal typical transportation mode with its stable connections, clear structures and timetables and ability to move masses $[4,39]$. The train provided a "one-best-way" solution for fast, direct, and calculable transportation of people and goods, qualities that mirror general socio-cultural tendencies in the first modernity such as heteronomy, stability, clear-cut societal institutions, and a search for clearness and unambiguity by purification $[4,39]$. In the second phase of modernity, direct connections and linear progress are substituted with non-directional change propelled by risk management, inconsistency, transience, and liquidity. Individual modes replace collective solutions for moving and organizing, and the privately owned car is the paradigmatic mobility mode. The second phase of modernity is socially and culturally structured around the individual, possession, autonomy, fluidity and suboptimal solutions, and the private car is a transportation mode embracing such lifestyles [4,39]. A third framing of modernity relies on "motile hybrids" [4,39]. These are constellations of bodies, technologies, physical spaces, knowledge, and skills in constant flow, where digital tools and technologies melt together with humans in a modernism characterized by pluralism, networks, air travel, internet, and fragmented mobilities. In this phase of modernity, ambivalence has become normality, and paradox solutions and temporality dominate political and planning efforts $[4,39]$. The radical changes in modernity in the mobile risk society stressed by Kesselring underline why mobility innovation is crucial at this time: 
though new phases of modernity and mobile living are emerging, the modes and solutions of previous stages in modernity keep iterating, for example when private cars-even if electrified-remain a dominant transportation mode in spite of developments towards a more flowing and networked modernity. The changing conditions of the second modernity, however, render possible new ways of mobile living and new cultures of mobilities.

Simultaneously with the massive transformations of the mobile risk society, awareness of climate change as the fundamental challenge in present time has arisen. Climate change profoundly questions modern lifestyles in the mobile risk society and amplifies the urgency of innovative sustainable solutions. Imminent climate disasters, carbon pollution, and massive urban congestion problems exhibit the crisis of modern mobility and the need for alternative and sustainable mobility systems beyond mass transportation, suboptimal individual solutions, and paradoxes preventing proper sustainable innovation. For decades, a dominating response to climate change and the need for creating alternative mobility futures has pointed to emerging technologies as the innovation that will transform mobilities. However, in the light of the mobile risk society and mobilities research, technology interventions such as electrified vehicles can be understood as iterating the existing carbonized system of automobility [38], because the socio-cultural practices and patterns sustaining the current carbonized mobility are not scrutinized [16].

One way to include cultures of mobilities in sustainable innovation is by engaging with everyday life in the mobile risk society as the scale of observation. Today, carbon-reliant motile hybrids permeate everyday life; we rely on them to commute to work, share ideas, consume goods, meet with friends, educate ourselves, pick up our children, etc. Everyday life is made up of social practices, perceptions and patterns that are deeply rooted in living in a mobile risk society. Zooming in on everyday life establishes a lens for exploring how habits, technologies, relations, communities, opportunities, practicalities, exclusion processes and ideas of what it means to work, live, consume and play enter into socio-technical networks and form cultures of mobilities. In an area where mobilities are interwoven with risks and no "one-best-way" or optimal solutions seems reachable, engaging with cultures of mobilities establishes a platform for experimenting with other possibilities for transitioning modern mobilities. We argue that a prerequisite for prompting lasting sustainable innovation is replacing technology fetishization with innovative engagement in the social and cultural processes and wider networks surrounding mobile everyday lives. Understanding urban cultures of mobility and their extensions in time and space is an essential part of stimulating sustainable innovation, both when aiming at picking the "low-hanging fruits" in sustainable mobility transition-which will be exemplified through the SIMS visionary workshop later in this article—and when planning sustainable mobilities for the livable city.

\section{Planning Sustainable Mobilities for the Livable City}

Having argued that technological innovations in the mobile risk society produce iterative mobilities, it is relevant to discuss how it is possible to transform this tendency into more innovative processes in urban mobilities planning. From the outset, an inclusive planning approach is adopted that emphasizes that future visionary urban living builds on transdisciplinary and cross-structural bottom-up planning practices [41,42], to paraphrase Friedmann [43] in his later works that stressed that planning should be transactive, communicative, collaborative and engage in continuous social learning. Furthermore, he describes planning processes as acts of dynamic balancing, "(Planning) seeks dynamic balances between the part and the whole, the technical and normative, the empirical and theoretical, the pragmatic and utopian, the near present and the distant future, exchange values and use values" [43]. Understood this way, urban planning processes should develop innovative solutions within the complexity of the mobile risk society. When planning moves towards increased collaboration and engagement of multiple actors in the process, instead of the usual suspects, the process becomes more open-ended $[41,44]$. In the case of urban mobilities planning, the open, innovative approach relates to the level of engagement among a multitude of actors involved in the development of 
future urban mobilities [45]. Instead of planning for actors and stakeholders, planning practices aim at planning with actors and stakeholders [42] as the entry point for sustainable development [46]. This entails an openness where mobility solutions in cities is not only relevant for transportation planners, but also for stakeholders and citizens engaged in the social and cultural aspects of what makes a city.

The argumentative turn in planning [47-49] for sustainable urbanities means that visions of the future city and its mobilities need to be transformed into specific frames, shapes, texts, and aesthetics where they become relevant and applicable for policies and everyday life [50]. Sandercock emphasis the power of stories and storytelling because "stories are central to planning practice: to the knowledge it draws on from the social sciences and humanities; to the knowledge it produces about the city; and to ways of acting in the city. Planning is performed through story, in a myriad of ways" [51]. With this starting point, storytelling in relation to the framing of sustainability and livability in cities plays a significant and powerful role not least in relation to future changes of perceptions and perspectives on mobilities $[18,50]$. This can be seen when cities around the world, throughout the last decades, have integrated sustainability in multiple parts of the planning arenas through stories and storytelling, not least on sustainable mobility [51,52]. Sustainability has become an essential and inevitable perspective of transforming cities into livable and innovative urban hubs that are attractive to citizens, guests, private and public investors, etc. [53,54]. They capitalize on performance criteria as livability, building upon the notion that a livable city is a prerequisite for modernity, and paradoxically enough, here the automobility system is not seen as essential for economic growth. In 2019 the list of most livable cities in the world included Vienna/Austria, Zurich/Switzerland, Vancouver/Canada, Auckland/New Zealand, Munich/Germany and Denmark/Copenhagen (https://www.archdaily.com/914233/these-are-the-20-most-livable-cities-in-the-world-in-2019). Rankings like these are numerous and so are the estimates of the outcome of such listings. Seen in this context, the eagerness to develop cities within a broad conceptualization of sustainability, where other mobilities than automobility dominate urban spaces, generates potential alternative innovative collaborations across different sectors. Planning for livable cities thereby also includes developing strategies and practices within the field of sustainable mobilities that do not favor car ownership and conventional car use as superior to alternative modes of mobilities. This implies that visions on sustainability and livability in urban areas are building on holistic approaches, methodologies, and practices [46].

The Story of Copenhagen as Innovation Lab for Sustainable Change?

Since 2012 the Municipality of Copenhagen, Denmark, has incorporated the goal of being the first carbon-neutral capital in the world by 2025 [55]. This is an ambitious vision involving rhetoric and reality. The vision is integrated into the majority of municipal plans, and sustainable mobility schemes are developed in the green mobility plan [56,57], in the action plan for implementation of SDGs within the existing policy field of the Municipality in 2018 [58], and in the overall municipal plans that set the general targets and guidelines for municipal development. As a lever for realizing the overall goal on carbon neutrality, the Municipality has moderated numerous collaborative processes that connected both internal, public partners and external, private stakeholders at multiple levels. Different types of cooperation have emerged combining individual agendas with common milestones and trans-sectorial practices within the existing structural framework. In the newest municipal plan from 2019, the City of Copenhagen approved the adjustment of their former goals on use of mobility modes. For a decade, the City of Copenhagen has worked strategically with the use of different modes: a minimum of one-third of trips by bicycle, a minimum of one-third of trips on public transportation, and a maximum of one-third of trips by car. For a long period that has been considered as a utopian-if not impossible-vision to fulfil, especially because the political maturity towards limiting the use of cars in the urban area was not clear and unequivocal. However, in 2019, the municipal plan of Copenhagen set out a new minimum with one-quarter of trips by bicycle, one-quarter of trips on public transportation, one-quarter of trips by pedestrians, and a maximum of one-quarter of trips by car [59]. Even if Copenhagen has quite a way to go to reach this goal, it nevertheless indicates a will to work towards 
new and more innovative distribution of urban mobilities, which allows for more approaches in planning without the car being center stage [10].

Despite the high-ranked sustainable profile and continuing ambitious visions and policies, Copenhagen is still far from reaching its ambitious goals. Copenhagen is witnessing a growth in car ownership of around 30\% since 2000 [60]. Congestion in and out of the city center is still growing, estimated to reach almost $150 \%$ by 2030 [61], and the increased amount of traffic generates increased pressure on the roads with critical influence on livability and sustainability measures. Despite these planning innovations and mobility governance, the Jevons paradox is constantly challenging planning objectives.

This calls for planning processes that are moving strategically from "traditional" iterative transportation planning with a sustainable vision (but still within silos) to a more holistic, innovative mobilities planning with sustainability as its starting point. The political goals in Copenhagen are operationalized through the implementation of traditional small-step initiatives that are continuously related to better public transportation, reduced parking norms, even better cycling infrastructures, better infrastructure for EVs, etc. However, it could be argued that the initiatives are not radical innovations insofar as the vision of carbon neutrality is far from being implemented. However, there is a growing political awareness about challenging more traditional measures, experimenting with cultural aspects such as car-free areas in the city, autonomous test busses, MaaS, etc. The interconnectedness between mobility and perspectives of growth (and speculations on how radical interventions related to mobility in the urban context can affect growth negatively) often still seem to challenge the sustainability discourse. So, what is still an open-ended and tricky question is how innovative processes can improve the connectivity between more individualized iterative initiatives-even in a sustainable and visionary bicycle-friendly capital like Copenhagen.

With this in mind, it can be argued that there is a momentum in Copenhagen and other western cities with a clear and fundamental sustainable profile for understanding and developing strong, decarbonized, and socially inclusive mobility systems. Livability in practice calls for creative solutions that enable sustainable everyday life in a globalized, reflexive modernity [5,51]. These aspects can be emphasized in dynamic planning approaches that are strategically thinking across structural traditions and organizational boundaries and acknowledging collaborative open-ended experiments as innovative and mandatory in sustainable urban development. In the following we use an example of a visionary workshop on MaaS solutions for three urban areas in Copenhagen that outlines a way to start experimenting with innovative approaches towards sustainable mobilities.

\section{Mobility Innovation by Harvesting the Low-Hanging Fruits: Experiences from a Visionary Workshop}

In March 2020, a visionary workshop was conducted as part of the Sustainable Urban Mobility Solutions (SIMS) project funded by the Innovation Fund Denmark. The overall purpose with SIMS is to provide comprehensive knowledge and experiments that offer substantial alternatives to private cars, by designing solutions whose point of departure is the complex of social practices and mobilities within the everyday life of citizens. The test sites for SIMS are Nordhavn (a newly developed urban area close to the city center), Nærheden (a newly developed area $30 \mathrm{~km}$ from Copenhagen), and Folehaven (an old working-class area outside the city center). These three areas are three quite different socio-geographical city districts within the capital region. As part of the empirical work in SIMS, we are conducting interviews and focus groups with the inhabitants of these areas and involving a variety of stakeholders in designing solutions for a test period. The visionary workshop we are using as an example in this article had the aim of gathering urban planning and mobility stakeholders to create a free space for them to imagine different solutions on the test sites. Essentially, the visionary workshop attempted to challenge mainstream techno-fixed "one-best-way" solutions by stimulating reflections and discussions about alternative and more comprehensive solutions designed with a starting point in contextual everyday mobilities. Thus, the three different case areas formed the empirical point of departure for discussions in the workshop. 
The workshop was prepared, scheduled, and run in order to facilitate discussions on alternative cultures of mobilities and imaginations of innovative future mobility solutions [46,62]. The framework condition about challenging the iteration of existing socio-technic automobility systems was clearly expounded to the participants in advance. In order to qualify comprehensive problem framings and solutions, workshop participants comprised a combination of interdisciplinary and prominent change agents within the Danish mobility scene. We invited 30 participants from different fields: city developers from the three test sites, urban planners from the Municipality of Copenhagen, public servants from the Ministry of Transportation, public and private mobility operators, sustainability experts, and researchers. The group was organized to obtain the widest possible spread of interdisciplinary professional backgrounds. The discussions were centered around the core questions How can we change the existing (unsustainable) infrastructures and cultures/norms through social and physical/material interventions? and more specifically, How can we change from individual car ownership to mobility sharing schemes, walking and cycling and public transportation? The workshop was organized around the three test sites with two hours allocated to discuss each site. We divided the participants into groups representing different disciplines. Each group was equipped with a big map of the test sites and a stack of symbolic probes like traffic signs, urban activities, materials, green areas, etc., which acted as a challenge kit to stimulate creative imagination for developing innovative solutions. Each workshop round was introduced by the responsible test site developer, including a brief status outline of the key mobilities opportunities and obstacles within the specific site. Following the group discussions, a common discussion with all workshop participants centering around a "fresh" map gathered together the various ideas.

The workshop discussions spurred a variety of fruitful inputs to the design of interventions. In opposition to smart techno-fixed innovation, the workshop created a kind of emancipatory space for elaborating already existing initiatives and practices in new urban configurations. The following extract from the workshop outlines the ideas for accommodating a sustainable mobility transition that are feasible thanks to manageable and accessible changes within existing material and social structures and practices. The ideas gathered from the workshop inform a reframing of the current "structural storytelling" $[63,64]$ and have the potential to influence future policy interventions and enhance innovative solutions in sustainable mobilities planning. The following is a summary of the essential findings.

\subsection{Stimulating and Cultivating Contextual Communities}

All three sites of intervention are home to a diversity of distinctive communities. Social relations between and across actors and networks (e.g., citizens, workers, employees, associations, etc.) offer a vast amount of resources, which can be profitably stimulated and activated in processes of change. Therefore, a prerequisite for designing interventions is to identify the prevailing community networks through mapping the specific characteristics of urban sites by investigating the essential contextual historical, cultural, social, and economic values. Mapping networks and identifying key actors and their significant role as drivers or front-runners was in general stated as a valuable strategy to promote, convey, and anchor new mobility schemes. Thus, a recurring highlighted strategy is to pinpoint potential actors to act as ambassadors for the innovative solutions. Network-stimulating activities to fertilize social interrelations are crucial core drivers to create the persuasive stories of experiences, which are anticipated to be mandatory for increasing recruitment and propelling new cultures of mobilities. This is very much in line with Beck's concept of sub-politics, which is a way for actors to work around the established political system in a risk society [65].

For example, the "blue-green" harbor and coast area, Nordhavn, branded as a sustainable and innovative urban district in Copenhagen, has attracted multiple small creative enterprises, public-private partnerships and a wide range of associations or networks (including architectural firms, a club for winter swimmers, the EnergyLab, etc.) which identify with a sustainable profile. Framing common interests between these actor networks was highlighted as a promising strategy 
to ensure robust business cases for shared mobility schemes. Nordhavn is an area with a very high socio-economic profile and has from the start been built with a lot of infrastructure for private cars. In this context, the network of small creative enterprises is seen as one that can show that successful businesses do not go hand in hand with individual car ownership and infrastructures to facilitate it.

In Folehaven, the context is completely different from Nordhavn. The socio-economic profile is very different, and parts of the area have been put on the Danish Ghetto list. In order to design sharing schemes for the local community, mobility solutions need to identify and consider the informal networks such as the card game or knitting clubs for elderly people living in homes belonging to non-profit housing associations as well as the young families moving out of the inner city to a one-family house. In the suburban area Nærheden (which in Danish means "nearby"), the socio-economic profile is closer to the one in Nordhavn and the area does not have any non-profit housing associations. Here the suggestion was to approach context-specific community networks, such as those concerning communal eating or running clubs. These context-specific communities are highlighted as potential springboards for launching alternative ways of mobilities.

\subsection{Testing and Experimenting as Windows of Opportunity}

Testing alternative mobility solutions for a temporary period is acknowledged as a powerful way to give citizens an experience that can create permanent change. Through strategies and storytelling about the sustainable and livable city, where urban spaces are redesigned for use other that by private cars, the experience of living in car-free areas can pave the way for experiencing alternative uses of urban spaces. This can be framed under the umbrella of tactical urbanism [66], in which experimentations in urban spaces are used to stimulate new urban cultures arranged and driven by multiple actors and users. In central Copenhagen this has already been used when redeveloping neighborhood streets with more emphasis on urban dwelling, cycling, walking, and public transportation [10]. Tactical urbanism exemplifies how user-driven micro-spatial strategies are relatively low-cost and straightforward to implement, such as the substitution of existing private parking places with ride-sharing schemes for a temporary period. Concerning the regeneration plans for Folehaven, temporary uses of the space are acknowledged as simple, feasible low-cost changes. At the workshop it was suggested that lines on the asphalt reserved for private car parking be replaced by alternative symbolisms allocating the spaces to car-, ride- or bike-sharing schemes, or by simple physical rearrangements such as flower pots and benches that are motivating recreational use and social encounters for citizens. Alternative uses can potentially reflect other purposes such as leisure, health, comfort, and convenience. These are purposes that are rarely mentioned in mobility planning processes and perhaps missing within existing everyday-life practices. Thus, the current challenges in Folehaven such as residents' loneliness, isolation, and discomfort when staying outside (due to a feeling of insecurity amongst elderly people) could possibly be met by producing new and more inclusive spaces for valuable social interactions and sharing (of mobility schemes).

Another example occurred within discussions about specific mobility interventions in Nærheden. Instead of privileging individual driving, the main road to the local school ought to prioritize soft and slow mobility modes. Instead of efficiency, acceleration, and speed, the problem framing aims to change the focus to how to ensure a desirable, delightful, and physically active beginning of the day for children on their way to school. In general, interventions like setting up signs or illustrations such as "no cars allowed", "one-way traffic", "car-free zones", and "pick-up zones" are anticipated as effective and simple low-cost operational tools to challenge existing infrastructures of private automobility. Thus, user testing and experiences with livability and alternative innovative approaches could certainly develop a new storytelling of greener, slower, and more sustainable everyday life.

The workshop discussions underpinned the effort to design innovative sustainable mobility modes as tightly incorporated in existing collectively-based transportation means. Recurrent recommendations were to upcycle public transportation modes by establishing sharing schemes in proximity, preferably within just a few minutes' walking-distance, from the present hubs. In all three sites of intervention, 
existing modes of public transportation are considered as obvious physical points for establishing sharing schemes. The specific interest in getting access to existing transportation hubs is in line with the overall municipal plan of Copenhagen where developing multi-modal stations is mentioned. Multi-modal stations offer a variety of functionalities such as shopping, having a coffee, workspaces, shipping points for products, collections point for vegetable, playgrounds for children. Adding to existing infrastructures in the form of enlarged hubs hosting, for example, car- and bike-sharing, electric scooters, and charging stations for electric cars would be strategically significant developments of sustainable multi-modal mobility. Alongside the mainstream assumption of MaaS as a matter of developing a smart user-friendly app that combines seamless mobility through profitable subscriptions (which is an idea that also came up during the workshops), expansion, and improvement of alternative substitutions within existing infrastructures are acknowledged as substantial within the discussions.

\subsection{Sustainable Mobilities Demand Alternative Powerful Intervention Framings}

In addition to harvesting the low-hanging fruits, the discussion among participants also touched upon a need for ambitious policy framings to discourage current individual car driving [67] by shifting the balance between competing practices. The idea of developing multi-modal public stations combined with a variety of social and material functions could obviously illustrate how ambitious policy interventions would take advantage of the increasing flexibility of work and work life (partly supported by digitalization and the internet) by developing infrastructures and cultures for reducing travel and stimulating new mobile practices $[4,39]$.

An example of radical discouragement of existing automobility infrastructures is proposed by a former city planner when discussing interventions in Folehaven. She suggested blocking the non-stop car traffic surrounding the city area, perhaps the most intensive main roads in Copenhagen, combined with a $20-\mathrm{km} / \mathrm{h}$ speed limit in general. In addition, she recommended thoroughly upgrading public transportation connections, which should go beyond the enlargement of the metro system in this specific area. Accordingly, a crucial and general recommendation was to acknowledge the need for economic regulations. Moreover, profitable mobility subscriptions, increased stringent regulation of car driving and parking taxes supplied with subsidies earmarked for sharing schemes are acknowledged as powerful, efficient tools. At the visionary workshop, there was a strong consensus among the actors that achieving carbon neutrality in 2025 involves massive and radical decisive regulation and legislation on current mobility structures.

Significantly, timing is also regarded as a key factor. Certainly, all the mobility operators agreed that sharing schemes in general take a long time to break even. Thus, a significant Danish car-sharing scheme participating in the workshop claimed a need for city planners and developers to allocate physical space to sharing schemes and facilities in the early pre-planning phases. Timing to attract and adopt newcomers is also crucial. However, changes or shifts in life phases and everyday-life practices such as relocations, having children, getting divorced, change of work place, etc., are recognized as significant moments for introducing alternative sharing schemes. The developer of Nærheden supports this strategy, and henceforth expects to promote car-sharing schemes within the future city branding. Specifically, the developer confirms they will focus on communicating the car-sharing opportunity as a valuable part of the future sales promotion. Overall, sustainable transportation solutions could more strategically strengthen a location's brand as a common sustainable identity, for instance by specific branding narratives such as "Nærheden is the place we are sharing".

\subsection{Summary of the Visionary Workshop Discussion}

Broad interdisciplinary cooperation is critically needed to add new significant impetus to support sustainable transformation changes in urban mobilities. The workshop challenged powerful hegemonic assumptions, including silo thinking and technology-reliant responses to climate change, by facilitating a space for elaborating innovative solutions rooted in everyday life in three different urban sites in the Greater Copenhagen area. Many of these solutions actually appear to be within reach in 
the near future, and thus comprise "low-hanging fruits" in sustainable mobility transition. Thus, the workshop approach illustrates the potential of contesting dominating assumptions to develop alternative approaches, and that interdisciplinary knowledge exchange across different knowledge systems and contexts (space and actors) is fundamental for the critical need to reframe current material infrastructures and cultures (norms and values).

In general, stimulating and activating the context-based community spirit is highlighted as a "game changer" to cause ripple effects for alternative cultures of mobilities, which is why identifying links and connections of arrangements for common sharing and meeting is underlined as crucial when designing future intervention points. User experiences are anticipated as essential in order to recruit people to test new modes of transportation, and to develop comprehensive designs for all kinds of needs. Allocating spaces for recreational, social, and cultural meeting points is fundamental for increasing community spirit and sharing facilities, which is why this is an agreed workable and powerful city-planning device for long-term alternative solutions. Sharing transportation modes with other people could simultaneously strengthen and improve social configurations. Technology innovation and user-friendly profitable subscriptions are decisive for future transformation, but story-telling occurred from the everyday perspective, and clear sets of overarching governance goals that ensure the enhancement of public value to change dominant automobility cultures are essential. Therefore, familiarity and know-how of sharing mobilities (access), instead of privatization (owning), are essential to break down prejudices and to merge new cultures that support alternative solutions. That this was on the agenda in the workshop could indicate a beginning of a move from a second to a third modernity as framed by Kesselring [39]. Certainly, the mobility operators agreed that sharing schemes in general requires a long time to break even. Therefore, the sharing schemes demand that city planners and developers allocate physical space to car-sharing schemes and sharing facilities in the early city planning phases.

\section{Conclusions}

This article began by arguing that technology iterations can operate as salient and often unacknowledged barriers to transitions towards sustainable mobilities. Iterations deploy culturally appropriate solutions to the climate crisis, and thereby form systemic anthropogenic risks, subject to what we call structural risk iterations. The structural risks iterations are grounded in the underlying imperatives around capitalism as a mode of organizing that leaves no other option than constant mobility. Iterations continue the mobile risk society by ways in which mobility cultures and the demand for mobility interlock "silos of techno-innovations". Rather than system innovations that aim to challenge Jevons' paradox and orchestrate the ambivalences of the mobile risk society, the deeply culturally embedded belief in technological innovation and energy efficiency as salient, climate-mobility risk solutions structurally impedes silo iterations. Hence, we argue that iterations do not address the ambivalences and risks of mobilities. Everyday mobilities practices, patterns and cultures are often left untouched by technological innovation. New decarbonized technologies often mime their carbonized predecessors in terms of design, appearance, and use (e.g., AI, AVs, and EVs), and therefore, cultural iteration persists in spite of novel technology innovation. The habits, structures and ideas of current carbonized mobility systems iterate systemic risks are not handled and any discussion of decreasing mobility as a way towards sustainable mobility is left out. The current challenge is therefore not merely to develop technologies capable of replacing the current monoculture of combustion-engine vehicles, but to understand cultural ideas of modern living, and how to enhance new sustainable cultures of mobilities and immobilities.

One way to include cultures of mobilities in sustainable innovation is by engaging with everyday life in the mobile risk society as the scale of observation. Today, carbon-reliant motile hybrids permeate everyday life; we rely on them to commute to work, share ideas, consume goods, meet with friends, educate ourselves, pick up our children, etc. Everyday life is made up of social practices, perceptions and patterns that are deeply rooted in living in a mobile risk society. Zooming in on everyday 
life establishes a lens for exploring how habits, technologies, relations, communities, opportunities, practicalities, and exclusion, as well as ideas of what it means to work, live, consume and play, enter into socio-technical networks and form cultures of mobilities. In an area where mobilities are interwoven with risks and no "one-best-way" or optimal solution seems reachable, engaging with everyday manifestations of cultures of mobilities establishes a platform for experimenting with other possibilities for transitioning modern mobilities and tackling systemic risks. We therefore argued that a prerequisite for prompting lasting sustainable innovation in mobility systems is ending the collective fetishization of new electrified technologies and engaging innovatively in the social and cultural processes and wider networks, in which modern everyday life is embedded.

Seen in the context of this article, the eagerness of developing cities within a broad conceptualization of sustainability, among several other perspectives, generates potential alternative innovative collaborations across different actors. Planning for sustainable livability in cities also includes developing strategies and practices within the field of sustainable mobilities that do not consider car ownership and conventional car use as superior to alternative modes and mobilities. This implies that the visions on sustainability and livability in urban areas are not only idealistic, brand-strengthening strategies on paper but also holistic approaches building upon new mindsets, methodologies, and practices in the planning system. In order to make an even more ambitious goal achievable, this calls for planning processes that move strategically from "traditional" iterative transportation planning with a sustainable vision (but still within silos) to a more holistic, innovative mobilities planning with sustainability as its premise/point of departure.

To discuss how innovation can take place, the article presented insights from a visionary workshop on "developing innovative sustainable mobility solutions" in three urban areas in Copenhagen. The themes identified in the workshop discussions show a willingness to elaborate on (and add to) existing knowledge and experience among the actors. Due to a worldwide climate change agenda and burning platforms of achieving specific, local goals, we argue that there is a momentum for identifying new forms of systemic innovation. Main findings were related to the need for stimulating and cultivating (contextual) communities, testing and experimenting as windows for opportunities, developing additions to existing infrastructures, and the notion that sustainable mobilities demand alternative powerful intervention framings. The open-ended process, which is a premise in this kind of workshop, is its strength, because planners and actors were set free to think across silos, but also (seen from a more traditional/short-term point of view) its structural weakness because the results are fuzzy and related to a change in mindsets around contexts, everyday-life complexities, and the mobile risk society (innovative thinking), rather than specific realizable plans and solutions with predictable outcomes measured in $\mathrm{CO}_{2}$, reduced number of trips, reduced number of parking lots, increased number of bicycles and passengers using the public transportation system, etc. Did the visionary workshop then create innovation? Of course, there are no clear answers here, partially because the specific interventions at the three sites are still not implemented, but the workshop identified possibilities for pushing iterative solution-based positions to more common alternative perspectives on local contexts and values that are identifiable across the actors' predictable interests and structurally dictated positions.

While it is crucial to consider the needs and actions within existing cultures of mobilities when designing successful substitutions [62,67], it seems more decisive than ever to reframe the contemporary increasing levels of "mobility need". Hence, forthcoming mobility transition forces us to interrupt conventional assumptions and reframe notions of norms and freedom connected to alternative mobilities. Despite the growing acknowledgement of the need to transform mobility norms, values and cultures, these issues were only superficially touched upon during the workshop discussions. Nevertheless, a workshop like this one also creates a common storytelling-a storytelling that, through influential actors within the mobility field, can begin to challenge existing meanings and notions around "the good life" and discuss alternative meaningful ways to perform and organize everyday lives with limited mobilities. 
And moving on from this, true innovation could be to initiate a discussion on limitations as something positive and not solely as reducing freedom. Instead of iterating the dominant notions and cultures of mobilities embedded in the risk society, a slower pace of life, with limits, could contain more freedom to do other, perhaps more meaningful things in everyday life. In many ways the COVID-19 crisis has created a momentum for exactly this. Not that the total standstill that COVID-19 produced is a positive vision for most, but it opens up the opportunity to be specific about what new versions of sustainable everyday life in new surroundings with new goals, meanings, and values are like. Alternative problem framings include questions such as: Where do we travel? How do homes look? Where and how do we live? With whom, when and why? How do we work? Where and how much? How do we feel? Instead of focusing on iterative technology-fixated innovation driven by green growth and liberal commercial interests, forthcoming intervention framing needs alterations to the urban landscape of what fertilizes and constitutes good livable urban places.

Author Contributions: All the authors of the article work together on the SIMS project and have contributed equally to the article. All authors have read and agreed to the published version of the manuscript.

Funding: This research was funded by Innovation Foundation Denmark.

Conflicts of Interest: The authors declare no conflict of interest.

\section{References}

1. Kahn Ribeiro, S.; Kobayashi, S.; Beuthe, M.; Gasca, J.; Greene, D.; Lee, D.S.; Muromachi, Y.; Newton, P.J.; Plotkin, S.; Sperling, D.; et al. Transport and Its Infrastructure. In Climate Change 2007; Metz, B., Davidson, O.R., Bosch, P.R., Dave, R., Meyer, L.A., Eds.; Cambridge University Press: Cambridge, UK, 2007.

2. European Environment Agency. Final Energy Consumption by Mode of Transport; European Environment Agency: Copenhagen, Denmark, 2020.

3. Beck, U. Risk Society: Towards a New Modernity; SAGE Publications Ltd.: London, UK, 1992.

4. Kesselring, S. The Mobile Risk Society. In Tracing Mobilities; Canzler, W., Kaufmann, V., Kesselring, S., Eds.; Ashgate: Aldershot, UK, 2008; pp. 77-102.

5. Freudendal-Pedersen, M.; Kesselring, S. Networked Urban Mobilities. In Exploring Networked Urban Mobilities: Theories, Concepts, Ideas; Freudendal-Pedersen, M., Kesselring, S., Eds.; Routledge: New York, NY, USA, 2018; pp. 1-19. [CrossRef]

6. Beck, U. Mobility and the Cosmopolitan Perspective. In Exploring Networked Urban Mobilities: Theories, Concepts, Ideas; Freudendal-Pedersen, M., Kesselring, S., Eds.; Routledge: New York, NY, USA, 2018; pp. 140-152.

7. Urry, J. Sociology beyond Societies: Mobilities for the Twenty-First Century; Routledge: London, UK, 2000.

8. Urry, J. The "System" of Automobility. Theory Cult. Soc. 2004, 21, 25-39. [CrossRef]

9. UN High-Level Advisory Group on Sustainable Transport. Mobilizing Sustainable Transport for Development; High-level Advisory Group on Sustainable Transport: New York, NY, USA, 2016.

10. Freudendal-Pedersen, M. Sustainable Urban Futures from Transportation and Planning to Networked Urban Mobilities. Transp. Res. Part D Transp. Environ. 2020. [CrossRef]

11. Bertolini, L. Planning the Mobile Metropolis: Transport for People, Places and the Planet; Palgrave Macmillan: London, UK, 2017.

12. Freudendal-Pedersen, M.; Kesselring, S. Exploring Networked Urban Mobilities: Theories, Concepts, Ideas; Routledge: London, UK, 2018.

13. Gehl, J. Life Between Buildings: Using Public Space; Island Press: Washington, DC, USA, 2011.

14. Amin, A.; Thrift, N. Cities: Reimagining the Urban; Polity Press: Cambridge, UK, 2002.

15. Lyubomirsky, S.; Sheldon, K.M.; Schkade, D. Pursuing Happiness: The Architecture of Sustainable Change. Rev. Gen. Psychol. 2005. [CrossRef]

16. Friis, F. An Alternative Explanation of the Persistent Low EV-Uptake: The Need for Interventions in Current Norms of Mobility Demand. J. Transp. Geogr. 2020, 83, 102635. [CrossRef] 
17. Hartmann-Petersen, K. Providing and Working in Rhythms. In Handbook of Urban Mobilities; Jensen, O.B., Lassen, C., Kaufmann, V., Freudendal-Pedersen, M., Lange, I.S.G., Eds.; Routledge: Abingdon, UK, 2020.

18. Freudendal-Pedersen, M.; Hannam, K.; Kesselring, S. Applied Mobilities, Transitions and Opportunities. Appl. Mobilities 2016, 1, 1-9. [CrossRef]

19. Hannam, K.; Sheller, M.; Urry, J. Editorial: Mobilities, Immobilities and Moorings. Mobilities 2006, 1, 122. [CrossRef]

20. Sovacool, B.K.; Griffiths, S. The Cultural Barriers to a Low-Carbon Future: A Review of Six Mobility and Energy Transitions across 28 Countries. Renew. Sustain. Energy Rev. 2020, 119, 109569. [CrossRef]

21. Steffen, W.; Crutzen, P.J.; McNeill, J.R. The Anthropocene: Are Humans Now Overwhelming the Great Forces of Nature? AMBIO 2007, 36, 614-621. [CrossRef]

22. Sims, R.; Schaeffer, R.; Creutzig, F.; Cruz-Núñez, X.; D’Agosto, M.; Dimitriu, D.; Meza, M.J.F.; Fulton, L.; Kobayashi, S.; Lah, O.; et al. Transport. In Climate Change 2014: Mitigation of Climate Change. Contribution of Working Group III to the Fifth Assessment Report of the Intergovernmental Panel on Climate Change; Edenhofer, O.R., Pichs-Madruga, Y., Sokona, E.F., Kadner, S., Seyboth, K., Adler, A., Baum, I., Brunner, S., Eickemeier, P., Kriemann, B., Eds.; Cambridge University Press: Cambridge, UK, 2014.

23. Heinold, A.; Meisel, F. Emission Rates of Intermodal Rail/Road and Road-Only Transportation in Europe: A Comprehensive Simulation Study. Transp. Res. Part D Transp. Environ. 2018, 65, 421-437. [CrossRef]

24. Helmers, E.; Leitão, J.; Tietge, U.; Butler, T. $\mathrm{CO}_{2}$-Equivalent Emissions from European Passenger Vehicles in the Years 1995-2015 Based on Real-World Use: Assessing the Climate Benefit of the European "Diesel Boom". Atmos. Environ. 2019, 198, 122-132. [CrossRef]

25. Davis, S.J.; Caldeira, K.; Matthews, H.D. Future $\mathrm{CO}_{2}$ Emissions and Climate Change from Existing Energy Infrastructure. Science 2010, 329, 1330-1333. [CrossRef] [PubMed]

26. Jevons, W.S. The Coal Question: An Inquiry Concerning the Progress of the Nation, and the Probable Exhaustion of Our Coal-Mines, 2nd ed.; Macmillan: London, UK, 1866.

27. Transport \& Environment. $\mathrm{CO}_{2}$ Emissions from Cars: The Facts; Transport \& Environment: Brussels, Belgium, 2018.

28. Kitchin, R. Getting Smarter about Smart Cities: Improving Data Privacy and Data Security; Data Protection Unit, Department of the Taoiseach: Dublin, Ireland, 2016.

29. Kitchin, R. The Real-Time City? Big Data and Smart Urbanism. GeoJournal 2014, 79, 1-14. [CrossRef]

30. Neirotti, P.; De Marco, A.; Cagliano, A.C.; Mangano, G.; Scorrano, F. Current Trends in Smart City Initiatives: Some Stylised Facts. Cities 2014, 38, 25-36. [CrossRef]

31. Mladenović, M.N. How Should We Drive Self-Driving Vehicles? Anticipation and Collective Imagination in Planning Mobility Futures. In The Governance of Smart Transportation Systems; Finger, M., Audouin, M., Eds.; Springer: New York, NY, USA, 2019; pp. 103-122.

32. City of Copenhagen. Analyse Af Københavns Kommunes Muligheder Og Udfordringer $i$ Forbindelse Med Udvikling Af Selvkørende Køretøjer; The Technical and Environmental Administration: City of Copenhagen, Denmark, 2017.

33. City of London. Mayor's Transport Strategy; Greater London Authority: London, UK, 2018.

34. Crayton, T.J.; Meier, B.M. Autonomous Vehicles: Developing a Public Health Research Agenda to Frame the Future of Transportation Policy. J. Transp. Health 2017, 6, 245-252. [CrossRef]

35. Urry, J. Societies Beyond Oil: Oil Dregs and Social Futures; Zed Books Ltd.: London, UK, 2013.

36. Beck, U.; Bonss, W.; Lau, C. The Theory of Reflexive Modernization: Problematic, Hypotheses and Research Programme. Theory Cult. Soc. 2003, 20,1-33. [CrossRef]

37. Curran, D. Risk Society and Marxism: Beyond Simple Antagonism. J. Class. Sociol. 2016, 16, $280-296$. [CrossRef]

38. Sheller, M.; Urry, J. The New Mobilities Paradigm. Environ. Plan. A 2006, 38, 207-226. [CrossRef]

39. Kesselring, S. Reflexive Mobilitäten. In Das Risiko-Gedanken übers und ins Ungewisse. Interdisziplinäre Aushandlungen des Risikophänomens im Lichte der Reflexiven Moderne. Eine Festschrift für Wolfgang Bonß; Pelizäus, H., Nieder, L., Eds.; Springer: Wiesbaden, Germany, 2019; pp. 165-204.

40. Freudendal-Pedersen, M. Searching for Ethics and Responsibilities of Everyday Life Mobilities: The Example of Cycling in Copenhagen. Sociologica 2014, 8, 1-23. [CrossRef] 
41. Healey, P. Collaborative Planning; UBC Press: Vancouver, BC, Canada, 1997.

42. Sandercock, L. Transformative Planning Practices: How and Why Cities Change. In Multiculturalism, Political Concepts in Sociology; Baumann, G., Vertovec, S., Eds.; Routledge: Abingdon, UK, 2011; pp. 157-179.

43. Friedmann, J. Insurgencies: Essays in Planning Theory; Routledge: Abingdon, UK, 2011.

44. Fischer, F.; Gottweis, H. (Eds.) The Argumentative Turn Revisited: Public Policy as Communicative Practice; Duke University Press: Durham, NC, USA, 2012.

45. Hartmann-Petersen, K.; Bennetsen, N. Mobilities Policies: Exploring Momentums as Urban Tipping Points in Practice. In Handbook on Methods and Applications for Mobilities Research; Büscher, M., Freudendal-Pedersen, M., Kesselring, S., Kristensen, N.G., Eds.; Edward Elgar Publishing: Northhampton, UK, 2020; pp. 231-240.

46. Freudendal-Pedersen, M.; Hartmann-Petersen, K.; Kjærulff, A.A.; Nielsen, L.D. Interactive Environmental Planning: Creating Utopias and Storylines within a Mobilities Planning Project. J. Environ. Plan. Manag. 2017, 60. [CrossRef]

47. Fischer, F.; Forester, J. (Eds.) The Argumentative Turn in Policy Analysis and Planning; Duke University Press Books: Durham, NC, USA, 1993.

48. Healey, P. Planning through Debate: The Communicative Turn in Planning Theory. In The Argumentative Turn in Policy Analysis and Planning; Fischer, F., Forester, J., Eds.; Duke University Press: Durham, NC, USA, 1993; pp. 233-253.

49. Hajer, M.; Dassen, T. Smart about Cities: Visualising the Challenge for 21st Century Urbanism; Nai010 Publishers: Rotterdam, The Netherlands, 2014.

50. Freudendal-Pedersen, M.; Kesselring, S. Mobilities, Futures and the City. Repositioning Discourses-Changing Perspectives-Rethinking Policies. Mobilities 2016, 11, 573-584. [CrossRef]

51. Sandercock, L. Out of the Closet: The Importance of Stories and Storytelling in Planning Practice. Plan. Theory Pract. 2003, 4, 11-28. [CrossRef]

52. Freudendal-Pedersen, M.; Kesselring, S.; Servou, E. What Is Smart for the Future City? Mobilities and Automation. Sustainability 2019, 11, 221. [CrossRef]

53. Campbell, S. Green Cities, Growing Cities, Just Cities? Urban Planning and the Contradictions of Sustainable Development. J. Am. Plan. Assoc. 1996, 62. [CrossRef]

54. Campbell, S.D. The Planner's Triangle Revisited: Sustainability and the Evolution of a Planning Ideal That Can't Stand Still. J. Am. Plan. Assoc. 2016, 82. [CrossRef]

55. City of Copenhagen. CPH 2025 Climate Plan: A Green, Smart and Carbon Neutral City; The Technical and Environmental Administration: Copenhagen, Denmark, 2012.

56. City of Copenhagen. Handlingsplan for Grøn Mobilitet (Action Plan for Green Mobility); The Technical and Environmental Administration: Copenhagen, Denmark, 2012.

57. City of Copenhagen. Handlingsplan for Grøn Mobilitet Opfølgning (Action Plan for Green Mobility-Follow Up); The Technical and Environmental Administration: Copenhagen, Denmark, 2017.

58. City of Copenhagen. The Capital of Sustainable Development. The City of Copenhagen's Action Plan for the Sustainable Devlopment Goals; The Technical and Environmental Administration: Copenhagen, Denmark, 2018.

59. City of Copenhagen. Kommuneplan 2019. Verdensby Med Ansvar. (Municipal Plan 2019. World City with Responsability, English Version Late 2020); The Finance Administration: Copenhagen, Denmark, 2019.

60. City of Copenhagen. København Får Flere Personbiler (Copenhagen Has an Increased Number of Private Cars); The Technical and Environmental Administration: Copenhagen, Denmark, 2016.

61. Boligministeriet, T.-B. Mobilitet for Fremtiden; Ministry for Transport, Building, and Housing: Copenhagen, Denmark, 2018.

62. Christensen, T.H.; Friis, F.; Freudendal-Pedersen, M.; Grindsted, T.S.; Hartmann-Petersen, K. Analytical Framework on Everyday Mobility Practices and Guidelines for Interventions; Aalborg University: Copenhagen, Denmark, 2019.

63. Freudendal-Pedersen, M. Mobility in Daily Life: Between Freedom and Unfreedom; Ashgate Publishing, Ltd.: Farnham, UK, 2009; Volume 2012.

64. Freudendal-Pedersen, M. Cyclists as Part of the City's Organism: Structural Stories on Cycling in Copenhagen. City Soc. 2015, 27, 30-50. [CrossRef]

65. Beck, U. The Reinvention of Politics: Rethinking Modernity in the Global Social Order; Polity: Cambridge, UK, 1997. 
66. Lydon, M.; Garcia, A. Tactical Urbanism: Short-Term Action for Long-Term Change; Island Press: Washington, DC, USA, 2015.

67. Spurling, N.; McMeekin, A. Interventions in Practices: Sustainable Mobility Policies in England. In Social Practices, Interventions and Sustainability: Beyond Behaviour Change; Strengers, Y., Maller, C., Eds.; Routledge: London, UK, 2015.

(C) 2020 by the authors. Licensee MDPI, Basel, Switzerland. This article is an open access article distributed under the terms and conditions of the Creative Commons Attribution (CC BY) license (http://creativecommons.org/licenses/by/4.0/). 